\title{
O QUE É ISTO PARA MIM?
}

Rodrigo Toniol ${ }^{1}$

Estar com quem se ama e pensar em outra coisa: é assim que tenho os meus melhores pensamentos, que invento melhor o que é necessário ao meu trabalho. O mesmo sucede com o texto: ele produz em mim o melhor prazer se consegue fazer-se ouvir indiretamente; se, lendo-o, sou arrastado a levantar muitas vezes a cabeça, a ouvir outra coisa. Náo sou necessariamente cativado pelo texto de prazer; pode ser um ato ligeiro, complexo, tênue, quase aturdido: movimento brusco da cabeça, como o de um pássaro que não ouve nada daquilo que nós escutamos, que escuta aquilo que nós não ouvimos.

Barthes, 1987, p. 35, grifo do autor

O excerto citado é parte do desenvolvimento da concepção do prazer do texto, elaborada por Roland Barthes entre o final de 1972 e o início de 1973. Naquele momento, Barthes realizava um seminário na École Pratique des Hautes Études a respeito de um texto de Freud sobre a paranoia, cujo objetivo, como ele mesmo declara no relatório enviado à École, não era o estudo de uma tese, mas a produção de "flashes de sentido", conforme a fórmula nietzschiana do "sentidos para mim". No verão de 1972, pouco antes de escrever o trecho acima e de conduzir o seminário, Barthes participara do famoso colóquio de Cerisy sobre Bataille. Nessa ocasião, mobilizado pelo tópico "Que e quem?”, Barthes manifestou-se²:

1 Doutor em antropologia social pela Universidade Federal do Rio Grande do Sul. Pesquisador do departamento de filosofia e estudos de religiáo, Utrecht University. Projeto de pesquisa apoiado pela FAPESP (2015/18386-8). Contato: rodrigo.toniol@gmail.com

2 Alguns trechos deste parágrafo e, sobretudo, as conexôes nele apresentadas estão presentes na introdução da obra O erotismo, de George Bataille, escrita por Raúl Antelo.

Debates do NER, Porto Alegre, ANo i8, N. 31, P. I25-I33, Jan./Jun. 2017 
O saber diz de todas as coisas: "o que é?" O que é o dedão? O que é este texto? Quem é Bataille? Mas o valor, segundo a palavra de ordem nietzschiana, prolonga a pergunta: o que é isto para mim? O texto de Bataille responde de maneira nietzschiana à pergunta: o que é o dedão do pé, para mim, Bataille? E, por deslocamento: o que é este texto, para mim, que o leio? (Resposta: é o texto que eu desejaria ter escrito).

Faz-se, pois, necessário - e talvez urgente - reivindicar abertamente em favor de certa subjetividade: a subjetividade do náo-sujeito oposta ao mesmo tempo à subjetividade do sujeito (impressionismo) e à não-subjetividade do sujeito (objetivismo). Pode-se conceber essa revisão sob duas formas: primeiro, reivindicar em favor do para mim que está em tudo: “o que é?", pedir e proteger a intrusấo do valor no discurso do saber. A seguir, atacar o quem, o jeito da interpretação; ainda aqui, Nietzsche: "Não se tem o direito de perguntar quem afinal interpreta? É a própria interpretação, forma da vontade de poder, que existe (não como um 'ser', mas como um processo, um devir) enquanto paixão..."; "não há sujeito, mas uma atividade, uma invenção criadora, nem 'causas' nem 'efeitos"' (Barthes, 1988, p. 257, grifo do autor).

Além de delinear uma espécie de zona de convergência (não sem tensões) que congrega Bataille, Leiris e Barthes - e que, do ponto de vista disciplinar, também poderia servir para indicar como as fronteiras entre antropologia, literatura e filosofia se desfazem em seus textos -, quero reter duas dimensóes dos trechos citados. Ambas, embora de naturezas distintas, estão relacionadas com a potente pergunta "O que é isto para mim?" A primeira dimensão justifica as características deste comentário, uma vez que ele é, antes de tudo, uma reação indisciplinada ao ensaio Le sacré dans le vie quotidien, de Michel Leiris. Ou seja, a forma deste texto atende a uma provocação: O que "Le sacré dans le vie quotidien" é para mim? É certo que o "para mim" não é uma característica particular deste comentário em si, mas uma condição da autoria. Ainda assim, aposto em dar visibilidade a essa condição para explicitar, de saída, que neste texto não tentarei mobilizar recursos para ultrapassá-la e, assim, falar em nome de qualquer hipotético "nós”. Essa é a primeira dimensão dos trechos citados que quero reafirmar - uma dimensão relativa à forma do comentário. 
A segunda dimensão da pergunta "O que é isto para mim?" que quero reter diz respeito ao conteúdo do que desenvolverei brevemente. Essa pergunta sintetiza o modo pelo qual Barthes interpela o texto de Bataille. Ao mesmo tempo, tal formulação também está implícita na obra $O$ erotismo, de modo que o comentador, Barthes, opera um movimento circunvolutivo, fazendo da pergunta que mobiliza o texto analisado, de Bataille, seu próprio ponto de partida e fundamento para a análise. Em certa medida, assumo uma postura correlata a de Barthes com relação ao texto de Leiris. Isso porque, muito mais explicitamente que o próprio Bataille, Leiris inicia o texto Le sacré dans le vie quotidien com um conjunto de questóes, sendo as principais - e duas primeiras -: "O que é, para mim, o sagrado? Mais exatamente: em que consiste o meu sagrado?” Aí estamos de volta a pergunta fundante para Bataille e para Barthes: “o que é isto para mim?” Há, no entanto, arrisco, uma diferença importante entre o "Eu" a que se referem Bataille e Leiris quando tratam do "para mim".

Leiris é explícito ao endereçar a pergunta sobre o que é o sagrado às suas próprias experiências. É a partir da descrição delas que conclui qual é o seu sagrado, um sagrado forjado no cotidiano, no ordinário e no não-oficial. Leiris insinua que todos temos nossos próprios sagrados e que poderíamos encontrá-lo a partir das memórias de um período específico da vida, a infância. Note que este é o único trecho do texto de Leiris em que a terceira pessoa rege a fala, cito:

Parece evidente que tudo o que nos fascinou durante a infância e nos deixou a lembrança de uma perturbação semelhante deve ser questionado em primeiro lugar. De fato, de todos os materiais de que podemos dispor, os que são extraídos das brumas da infância têm alguma chance de representar os menos sofisticados (grifo nosso).

Todo o restante do texto é dominado pelo relato do Eu, um tipo de economia fenomenológica do sagrado. No revólver de seu pai, na pista de corrida que frequentava, nas palavras que proferia, ali estava o sagrado de 
Leiris. No último parágrafo, o autor abre uma nova concessão ao tom de relato para recomendar que a reflexão sobre o sagrado seja feita, por todos, a partir escrutínio da memória do Eu:

Mesmo que um dos objetivos mais "sagrados" que um homem possa se propor seja adquirir um conhecimento de si táo preciso e intenso quanto possível, revela-se desejável que cada um, perscrutando suas lembranças com o máximo de honestidade, examine se não pode descobrir algum indício que lhe permita discernir nisso que cor tem para si a própria noção de sagrado.

Aí reside a diferença entre o endereço da pergunta "O que é isto para mim?” quando feita por Leiris e por Bataille. Se, como sugeri, para Leiris o que interessa nessa questáo é a possibilidade de explorar a fenomenologia do sagrado, isso é, o sagrado do Eu, para Bataille o que está em jogo é um "Eu" com subjetividade individual esvaziada.

Não cabe aqui fazer uma digressão sobre os vínculos entre o erotismo e o sagrado em Bataille, basta dizer que o "erotismo sagrado" constitui uma das três, se não a mais fundamental, formas do erotismo. Por enquanto, não é a definiçáo de sagrado ou de erotismo sagrado dada por Bataille o que importa, mas sim o modo que ele procede para delineá-la. Ao contrário de Leiris, Bataille não recorre às experiências do Eu individual para tratar do sagrado, mas apela a um Eu que transcende ao indivíduo, figura que na tradição antropológica talvez se sintetize na ideia de "pessoa", manifestada por Marcel Mauss (1974). É por isso que quando Bataille trata do erotismo sagrado "para mim" o que está em jogo é sempre um "Eu expandido". Por exemplo, no trecho a seguir, no qual é a pessoa do Ocidente e do Oriente a expressão das possíveis variaçóes das formas de erotismo:

[...] a ideia do erotismo sagrado é menos familiar. A expressão, aliás, é ambígua, na medida em que todo erotismo é sagrado, mas encontramos os corpos e os coraçóes sem entrar na esfera sagrada propriamente dita. Ao passo que a busca de uma continuidade do ser levada a cabo sistematicamente para além do mundo imediato designa uma abordagem essencialmente religiosa; sob sua forma familiar no Ocidente, o erotismo sagrado se confunde 
com a busca, exatamente com o amor por Deus, mas o Oriente procede a uma busca similar sem necessariamente colocar em jogo a representação de um Deus. (Bataille, 2014, p. 39-40)

$\mathrm{O}$ "Eu" de Bataille, que interessa para o delineamento da ideia de erotismo sagrado, não se refere a um "sujeito fenomenológico específico", mas a um "Eu" implicado em certa configuração histórica. Num diálogo imaginado, Bataille talvez perguntaria a Leiris: onde está a pessoa na economia fenomenológica do seu sagrado?

Experimentando outras referências possíveis e que transcendem a antropologia, numa tentativa de reproduzir a circulação disciplinar que Leiris e Bataille inspiram, podemos retomar a crítica que a filósofa Judith Butler faz a ideia do "relato de si mesmo".

Assim como existe uma ação performativa e alocutária executada por esse "eu", há um limite ao que o "eu" pode realmente recontar. Esse "eu" se fala e se articula, e ainda que pareça fundamentar a narrativa que conto, ele é o momento mais infundado da narrativa. A única história do que o "eu" não pode contar é a história de seu próprio surgimento como "eu" que, além de falar, relata a si mesmo. Nesse sentido, há uma história sendo contada, mas o "eu" que a conta, que pode aparecer nela como narrador em primeira pessoa, constitui um ponto de opacidade e interrompe a sequencia, induz uma quebra ou erupção do não narrável no meio da historia. Desse modo, a historia que conto de mim mesma, destacando o "eu" que sou e inserindo-o nas sequencias relevantes de uma coisa chamada "minha vida", deixa de relatar a mim mesma no momento em que apareço. Com efeito, apareço como aquela de quem nenhum relato pode ou será dado. Estou fazendo um relato de mim mesma, mas não há relato a ser feito quando se trata da formação desse "eu" que fala e que narraria sua vida. Quanto mais eu narro, mais provo ser menos capaz de fazer um relato de mim mesma. O "eu" arruína minha história, apesar de suas melhores intençōes. (Butler, 2015, p. 89, grifo do autor). 
Se avançada, essa poderia ser uma crítica ao percurso tomado por Leiris para falar do seu sagrado. Esse não é meu objetivo. Aqui a citação de Butler serve para dar continuidade às indicaçôes das diferenças entre o tipo de "Eu" a que Bataille e Leiris se referem quando coincidem com a questão "o que é isto para mim?" Além disso, sustento que a citação de Butler ajuda a esclarecer o "Eu" mobilizado por Bataille para falar do seu erotismo sagrado. Afinal, esse trecho não poderia ser compatibilizado com aquele já citado anteriormente, de autoria de Barthes que, a partir de Nietzsche, comenta a obra de Bataille? Permito-me reproduzi-lo novamente:

"Não se tem o direito de perguntar quem afinal interpreta? É a própria interpretação, forma da vontade de poder, que existe (não como um 'ser', mas como um processo, um devir) enquanto paixão...”; "não há sujeito, mas uma atividade, uma invenção criadora, nem 'causas' nem 'efeitos”.

Finalmente chego perto do ponto em que posso assumir a provocativa pergunta que intitula esse texto. Refiro-me ao ponto a partir do qual posso explicitar como a questão "O que é isto [o sagrado] para mim?" também pode assumir um valor metodológico. É isso que pretendo apresentar, ainda que brevemente, a seguir, situando como essa pergunta pode ser entendida como o fundamento da investigação que tenho atualmente conduzido.

O uso que faço do "para mim" não investe numa descrição da economia fenomenológica do sagrado, tal como para Leiris, mas indica o interesse por uma forma de vontade de poder sobre a experiência do sagrado do Outro. Náo me interessa a narrativa do "Eu não-pessoa" sobre o seu sagrado particular - inclusive arriscaria dizer que, tal como Butler, duvido da realidade absoluta desse lugar narrativo. Ao mesmo tempo, náo estou interessado em denunciar que por trás dos relatos de si sobre o sagrado há uma pessoa ou, nas palavras de Butler, de explicitar que "quando o 'eu' busca fazer um relato de si mesmo, pode começar consigo, mas descobrirá que esse 'si mesmo' já está implicado numa temporalidade social que excede suas próprias capacidades de narração” (Butler, 2015, p. 18). 
Em contrapartida, o que tem me mobilizado atualmente é descrever como uma forma especifica de vontade de saber passa a se interessar e a interpretar as variaçóes das experiências do Eu com o sagrado. Explico. O tema fundamental de minha pesquisa atual (Toniol, 2016; ver Toniol, 2015; Giumbelli; Toniol, 2017) são os usos, as apropriações e as variadas repercussões da categoria espiritualidade no campo das ciências médicas no Brasil. Precisamente, trata-se de investigar o modo pelo qual essa categoria tem emergido como uma variável em pesquisas dedicadas a identificar correlaçôes entre o "fator espiritual" e a saúde da população em geral, bem como de pacientes com perfis clínicos específicos. Para estabelecer essa correlação, os médicos pesquisadores precisam "descobrir" qual é a sua espiritualidade e, a partir daí, colocá-la em face da sua saúde.

Num primeiro levantamento identifiquei que no país existem pelo menos cinco centros de pesquisa, distribuídos em universidades do sul e do sudeste (USP, UNIFESP, UFMG, UFRGS e UFJF), que produzem dados e análises sobre o tema das relaçóes entre saúde e espiritualidade. Tais investigaçôes utilizam uma ampla gama de tecnologias que visam identificar, isolar e interpretar, a condição espiritual das pessoas e seus efeitos para a saúde. Elas buscam produzir correlaçóes como, por exemplo, "pessoas mais espiritualizadas tem menos problemas cardíacos". Diante do tema, estou especialmente interessados na criação e no uso das tecnologias de captura, ou melhor, de medida da espiritualidade, que vão de questionários ao mapeamento de atividades cerebrais, por parte dos cientistas engajados em alguns desses referidos grupos. A ênfase em tais tecnologias e instrumentos se deve ao fato de que além de constituírem a forma de “acesso" à espiritualidade, os questionários, as ressonâncias magnéticas e os mapeamentos de atividade cerebral são mediadores fundamentais para que a espiritualidade emerja como uma entidade clinicamente visível e avaliável para médicos e pesquisadores. A proposta da pesquisa que conduzo - que ainda está em fase inicial - é discutir, a partir das tecnologias de avaliação da espiritualidade, desenvolvidas e utilizadas no campo 
das ciências médicas, o modo pelo qual essa categoria tem sido articulada e tem mobilizado atores e instituiçóes dedicadas a promoção e aos cuidados com a saúde. Ressalto que não se trata de analisar esses dispositivos de avaliação da espiritualidade em si, mas concebê-los como parte fundamental de um processo de legitimaçáo da categoria "espiritualidade" no campo das ciências médicas, que pode nos dar algumas pistas sobre as características mais gerais desse processo.

Retomo as ideias que apresentei anteriormente para encerrar esse comentário. Há uma duplicidade na pertinência da pergunta "o que é isto [o sagrado/a espiritualidade] para mim?" para minha pesquisa. Primeiro uma pertinência empírica. Isso porque se alterarmos o sujeito ativo da sentença de "para mim" para "para você", nos deparamos com a pergunta fundamental dos médicos pesquisadores que estou investigando. No limite esse é o centro do interesse desses pesquisadores diante dos pacientes "o que é esta espiritualidade para você?” Das respostas a essa pergunta eles extraem números, estatísticas e dados que convertem o relato subjetivo em um indicador clínico. Já a segunda pertinência da questáo não está relacionada com as açôes dos meus sujeitos de pesquisa, mas sim a minha açáo diante deles. Quero indicar com isso que uma possível síntese dos interesses de minha investigação é descrever e refletir sobre como "o que é isto [o sagrado/a espiritualidade] para mim?” tem se tornado uma questão legítima para as ciências médicas. Nesse caso, o meu "para mim" é próximo ao de Bataille, isso é, não se refere a um sujeito, mas a configuração histórica de uma vontade de saber específica, a biomedicina. O que me interessa, noutra paráfrase, é a própria interpretação, a forma da vontade de poder e de saber, que existe (não como um 'ser', mas como um processo, um devir) na medicina com relaçáo a espiritualidade do Outro. Evidente, portanto, que metodologicamente náo é o sujeito que me interessa, mas uma atividade, uma invençâo criadora, nem causas nem efeitos. É assim que encerro esse curto comentário, advogando pela potência que o ensaio de Leiris oferece ao próprio modo pelo qual elaboramos nossas perguntas de pesquisa. 


\section{REFERÊNCIAS}

BARTHES, Roland. O prazer do texto. São Paulo: Perspectiva, 1987. . O rumor da língua. São Paulo: Brasiliense, 1988.

BATAILLE, George. O erotismo. Belo Horizonte: Autentica, 2014.

BUTLER, Judith. Relatar a si mesmo. Crítica da violência ética. Belo Horizonte: Autêntica, 2015.

MAUSS, Marcel. Uma categoria do espírito humano: a noção de pessoa, a noção do 'eu'. In: . Sociologia e antropologia. São Paulo: EPU/ EDUSP, 1974. p. 207-241.

GIUMBELLI, Emerson; TONIOL, Rodrigo. What is spirituality for? New relations between religion, health and public spaces. In: BLANES, Ruy; MAPRIL, Jose; GIUMBELLI, Emerson (Org.). Secularisms in a Postsecular Age? Religiosities and Subjectivities in Comparative Perspective, 2017. p. 147-167. TONIOL, Rodrigo. Espiritualidade que faz bem: Pesquisas, políticas públicas e práticas clínicas pela promoção da espiritualidade como saúde. Sociedad y religión, n. 43, 2015, p. 110-146.

- Capturando a espiritualidade: pesquisas médico científicas sobre a dimensão espiritual da saúde no Brasil. Projeto de pesquisa. São Paulo: FAPESP, 2016.

Recebido em: 10/12/2016 Aprovado em: 20/02/2017 
